\title{
Article
}

\section{Multifaceted falls prevention can help to reduce fall rates in high-risk and healthy community-dwelling older adults}

Palmer, Karen, Hill, James Edward and Clegg, Andrew

Available at https://clok.uclan.ac.uk/34471/

Palmer, Karen, Hill, James Edward orcid iconORCID: 0000-0003-1430-6927 and Clegg, Andrew orcid iconORCID: 0000-0001-8938-7819 (2020) Multifaceted falls prevention can help to reduce fall rates in high-risk and healthy community-dwelling older adults. Evidence-based nursing . ISSN 1367-6539

It is advisable to refer to the publisher's version if you intend to cite from the work. http://dx.doi.org/10.1136/ebnurs-2020-103291

For more information about UCLan's research in this area go to http://www.uclan.ac.uk/researchgroups/ and search for <name of research Group>.

For information about Research generally at UCLan please go to http://www.uclan.ac.uk/research/

All outputs in CLoK are protected by Intellectual Property Rights law, including Copyright law. Copyright, IPR and Moral Rights for the works on this site are retained by the individual authors and/or other copyright owners. Terms and conditions for use of this material are defined in the policies page.

\section{CLoK}

Central Lancashire online Knowledge www.clok.uclan.ac.uk

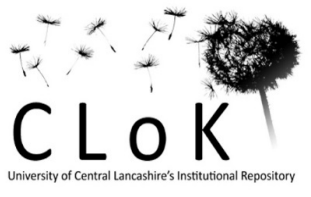




\section{Category:}

\section{Study type: Multifaceted falls prevention can help to reduce fall rates in high risk and healthy community-dwelling older adults.}

\section{Author's declarative title:}

Commentary on: Lee S H, Yu Soyoung. Effectiveness of multifactorial interventions in preventing falls among older adults in the community: A systematic review and meta-analysis International Journal of Nursing Studies 2020.

\section{Commentary Implications for practice and research}

- Multifaceted falls prevention is effective in reducing fall rates for high risk and healthy community-dwelling older adults.

- Exercise or an environmental modification component are important moderating factors in the effectiveness of multifaceted falls prevention in community-dwelling older adults.

- Further high-quality research is required in the exploration of important mediating factors in the effectiveness of multifactorial interventions for falls prevention in community-dwelling older adults.

\section{Context}

A fall is a defined as an event which causes a person to, unintentionally, rest on the ground, and is not a result of a major intrinsic event or hazard (1). Falls have both a significant clinical and psychological impact on the person and can place increased demands on the healthcare systems with the potential to increase both morbidity and mortality in older adults (2).

There are numerous risk factors associated with falls in older adults (3). This systematic review and meta-analysis aims to provide an up-to-date review of the effectiveness of multifactorial fall prevention interventions for older adults living in the community (3).

\section{Methods}

This systematic review undertook a comprehensive literature search of three databases. Studies published between 1994 and the $31^{\text {st }}$ March 2019 were used without explanation for the exclusion of historical evidence. Only randomised 
controlled trials (RCTs) reporting on multifactorial fall prevention programmes in the community setting were included. The outcome measures from the included studies were either the total number of people that fell or individual fall rates. Abstract title, full paper screening and data extraction were undertaken by two independent reviewers. A third reviewer was used to resolve any discrepancies. A robust assessment of bias was undertaken using the Cochrane Risk of Bias for Randomised Controlled Trials Tool. An appropriate meta-analysis was undertaken using a random effects model.

\section{Findings}

For the forty-five RCTs included in the review there were three main concerns these were risk of bias - of unclear/no allocation concealment, blinding of participants and blinding outcome assessment. There was moderate to substantial heterogeneity for all statistically significant comparisons.

The review found that multifactorial interventions produced a clinical and statistically significant $(p=<0.01)$ reduction in fall rates and number of people experiencing falls in the subgroup of "healthy older adults" compared to usual care. There was also a statistically and clinically significant reduction in fall rates in the high-risk group compared to control but not for the number of people experiencing falls. There was also no statistically significant difference for the frail group for both outcomes.

Multifactorial interventions which contained either an exercise or an environmental modification component had a clinical and statistically significant reduction in fall rates and number of people experiencing falls compared to control.

\section{Commentary}

This review enhances the findings of a previous systematic review by considering a larger range of publications on the effectiveness of multifactorial fall prevention intervention among community-dwelling older adults. For the first time, a comparison has been conducted comparing subgroups that differ in terms of the participants' risk of falls and the components and intensity of the intervention. Using the AMSTAR 2 Critical Appraisal Tool for systematic reviews, it was deemed that this systematic review provides an accurate and comprehensive summary of the results of the available studies that address the question of interest (4).

However, when interpreting this review it is important to take into consideration that there was limited allocation concealment, blinding of participants and outcome assessment and unexplained moderate to severe heterogeneity in all comparison except the frail subgroup analysis. Subsequently the estimated effects within this review may differ from the true effect but due to the large effects demonstrated in this review, it is likely that the true effect will be of clinical significance.

Due to the varying levels of effect, future high-quality research should explore possible mediating factors for the effectiveness of multifaceted falls prevention. This 
review did not explore adverse events, therefore future research and reviews should ensure that this outcome is reported, in particular with frail and high-risk adults.

\section{References}

1. Public Health England. Falls: Applying All Our Health; 2020. Available from: https://www.gov.uk/government/publications/falls-applying-all-our-health/fallsapplying-all-our-health

2. James $S \mathrm{~L}$, Lucchesi $\mathrm{L} R$, Bisignano $\mathrm{C}$ et al The global burden of falls: global, regional and national estimates of morbidity and mortality from the Global Burden of Disease Study. Injury Prevention. 2020; 1-9.

3. Lee S H, Yu Soyoung. Effectiveness of multifactorial interventions in preventing falls among older adults in the community: A systematic review and metaanalysis International Journal of Nursing Studies 2020.

4. Shea B J, Reeves B c, Wells G, Thuku M, Hamel C, Moran J, Moher D, Tugwell P, Welch V, Kristjansson E, Henry D A. AMSTAR 2: a critical appraisal tool for systemativ reviews that include randomised or non-randomised studies of healthcare interventions, or both. BNJ. 2017 Sep 21; 358: j4008.

\section{Commentator details}

Name: James Edward Hill

Affiliation: University of Central Lancashire

Correspondence address:

University of Central Lancashire,

Preston,

Lancashire

PR1 2HE

Email: Jehill1@uclan.ac.uk

\section{Competing interests}

I have no conflicts of interest with any aspect of this publication.

Acknowledgements: This report is independent research funded by the National Institute for Health Research Applied Research Collaboration North West Coast (ARC NWC).

The views expressed in this publication are those of the author(s) and not necessarily those of the National Institute for Health Research or the Department of Health and Social Care. 